\section{Publications}

We are proud to announce that the Proceedings of ICCMSE 2021 will be published in the very famous AIP (American Institute of Physics) Conference Proceedings.

The journals in which selected Proceedings of ICCMSE 2021 will be published are:

1. Journal of Numerical Analysis, Industrial and Applied Mathematics (JNAIAM) (ESCMSET), which is the official journal of European Society of Computational Methods in Sciences and Engineering

2. Journal of Mathematical Chemistry (Springer)

3. Journal of Computational Methods in Sciences and Engineering (JCMSE)

For Publication you must contact via email Professor Dr. Theodore E. Simos at:

chairman@iccmse.org

The conference organizers invite colleagues to submit proposals for Sessions, or Workshops and Minisymposia.

Each session should have at least 6 presentations and each Workshop or Minisymposium at least 12 presentations.

The Session, Workshop or Minisymposium organizers will be responsible for advertising their session, reviewing and selecting the papers.

Session organizers will have one presentation free. The Workshop or Minisymposium organizers will have free registration, accommodation and two presentations. Papers accepted for Sessions, Workshops or Minisymposia will be published in the Proceedings of ICCMSE 2021.

After the Conference papers presented at the Sessions, Workshops or Minisymposia will be considered for publication in the journals mentioned above.

\section{Galaxy Hotel Iraklion}

Heraklion, Crete, Greece

\section{ICCMSE 2021}

\section{7th International}

Conference of

Computational Methods

in Sciences and

Engineering

(ICCMSE 2021)

\section{4-7 September 2021, Heraklion, Crete, Greece}
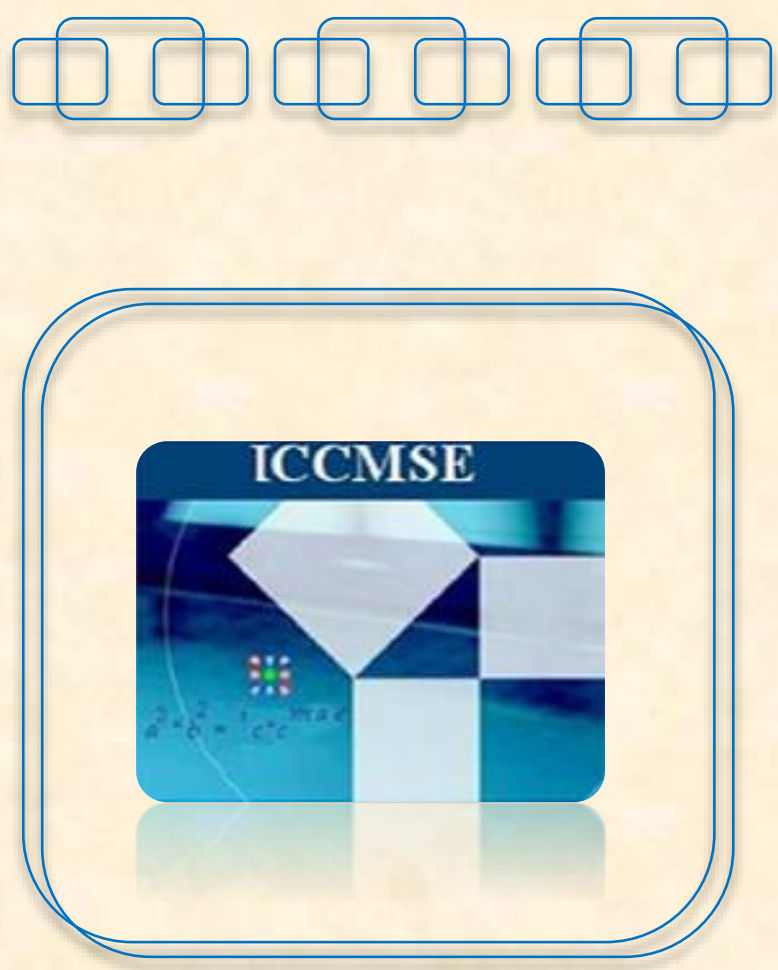

www.iccmse.org

\title{
INVITED SPEAKERS
}

\section{Prof. Dr. Paul Mezey}

Canada Research Chair in Scientific Modeling and Simulation, Editor Department of Chemistry, and Department of Physics and Physical Oceanography, Memorial University of Newfoundland, 283 Prince Philip Drive, St. John's, NL, A1B 3X7, CANADA, Permanent Guest Professor, Institute of Chemistry, University of Budapest, Hungary and Permanent Guest Professor, Babes-Bolyai University, Cluj, Romania 


\section{Dates of Importance}

\begin{tabular}{|l||l|}
\hline $\begin{array}{l}\text { Proceedings paper (3-4 } \\
\text { pages) submission deadline }\end{array}$ & 06 July 2021 \\
\hline \hline $\begin{array}{l}\text { Notification of acceptance / } \\
\text { referees' amendments }\end{array}$ & 11 July 2021 \\
\hline $\begin{array}{l}\text { Submission of the source } \\
\text { files of the camera ready } \\
\text { short papers to AlP } \\
\text { Conference Proceedings }\end{array}$ & 21 September 2021 \\
\hline \hline \begin{tabular}{l} 
Conference \\
\hline $\begin{array}{l}\text { Submission of the full } \\
\text { papers for publication in } \\
\text { conference syndicated } \\
\text { journals }\end{array}$
\end{tabular} & 10 September 2021 - \\
\hline \hline
\end{tabular}

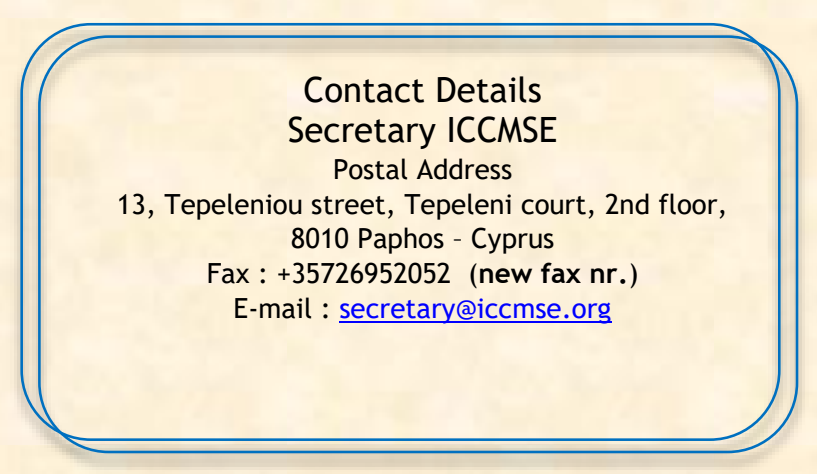

\section{Aims and Scope}

The aim of ICCMSE 2021 is to bring together computational scientists and engineers from several disciplines in order to share methods, methodologies and ideas and to attract original research papers of very high quality.

\section{Topics}

Topics to be covered include (but are not limited to):

- Computational Mathematics, Theoretical Physics, Computational Physics,

- Theoretical Chemistry, Computational Chemistry, Mathematical Chemistry,

- Computational Engineering, Computational Mechanics,

- Computational Biology and Medicine,

- Computational Geosciences and Meteorology,

- Computational Economics and Finance,

- Financial Forecasting,

- Scientific Computation,

- High Performance Computing,

- Parallel and Distributed Computing,

- Visualization,

- Problem Solving Environments,

- Software Tools,

- Advanced Numerical Algorithms,

- Modelling and Simulation of Complex Systems,

- Web-based Simulation and Computing,

- Grid-based Simulation and Computing,

- Computational Grids,

- Fuzzy Logic,

- Application of Nano Materials

- Hybrid Computational Methods,

- Data Mining and Information Retrieval,

- Virtual Reality,

- Reliable Computing,

- Image Processing,

- Computational Science and Education.

\section{Scientific Committee}

\section{Chairman}

Prof. T. E. Simos

College of Sciences, Department of Mathematics, King Saud University, Saudi Arabia and Laboratory of Computational Sciences, Department of Computer Science and Technology, University of Peloponnese, Tripolis, Greece, Member of the Presidium of the European Academy of Sciences, President of the European Society of Computational Methods in Sciences and Engineering (ESCMSE), Active Member of the European Academy of Sciences and Arts

(EASA), Active Member of the European Academy of Sciences (EAS), Corresponding Member of European Academy of Arts, Sciences and Humanities (EAASH).

\section{Vice Chairmen}

Professor Dr. Zacharoula Kalogiratou

Technological Educational Institute of Western Macedonia, Greece

\section{Associate Prof. Dr. Theodore Monovasilis}

Technological Educational Institute of Western Macedonia, Greece

\section{Scientific Committee}

Prof. Zacharoula Kalogiratou, Greece

Prof. Paul G. Mezey, Canada, Hungary and Romania

Associate Prof. Theodore Monovasilis, Greece Dr. Taku Onishi, Japan, Norway

Prof. T.E. Simos, Greece

Prof. Dr. Ajit J. Thakkar, Canada Prof. Ch. Tsitouras, Greece

Prof. Zhigang Jiang, USA 